\title{
Are serum bile salt concentrations raised in hyperlipidæmia?
}

\author{
G J BECKETT, J G DOUGLAS, N D C FINLAYSON, AND I W PERCY-ROBB \\ From the Clinical Chemistry Department, University of Edinburgh, and The Gastrointestinal and Liver Service, \\ The Royal Infirmary, Edinburgh
}

SUMMARY We have studied serum fasting and postprandial primary bile salt concentrations in a group of 10 consecutive hyperlipidaemic subjects. The efficiency of hepatic bile salt clearance in the same subjects was also studied using an injected dose of sodium glycocholate. No increases in serum fasting or postprandial concentrations of the primary bile salts were observed and hepatic bile salt clearance was only marginally abnormal in one subject. The presence of hyperlipidaemia does not invalidate the use of serum conjugated bile salt analysis for the detection of liver disease.

Serum bile salt measurements have been held by many workers to provide a sensitive index of liver disease. ${ }^{1-4}$

One attraction of the measurement of bile salt concentrations in serum is the apparent specificity of the measurements, an advantage not shared by the more conventional measurements such as bilirubin concentration and alanine aminotransferase and alkaline phosphatase activities. However, Pennington et al. ${ }^{5}$ have reported that nine out of 12 patients with type II and type IV hyperlipidaemia had on average a 10-fold increase in the concentration of bile salts in serum. These increases were greater than were found in patients with liver disease in the same study. These findings have potentially serious implications for the use of serum bile salt concentrations in the diagnosis of liver disease, especially when one considers the relatively high prevalence of hyperlipidaemia.

We have measured the serum (fasting and postprandial) concentrations of bile salts in a group of subjects with untreated hyperlipidaemia and who had no evidence of liver disease. The hepatic clearance of an injected bolus of glycocholate was also studied.

\section{Methods}

\section{SUBJECTS}

Formal consent was obtained from each subject and the study was approved by the Physicians Advisory Ethical Committee. Patients taking drugs known to

Received for publication 10 October 1979 induce the hepatic microsomal enzyme systems were omitted from the studies.

CONTROL SUBJECTS

Thirteen control subjects were studied: five were healthy volunteers (three males, two females), and eight were patients (four males, four females) whose disease did not involve the liver. These subjects were selected so that data over a range of ages similar to the subjects with hyperlipidaemia were obtained. Two patients had ischaemic heart disease without cardiac failure, and one each had rectal carcinoma without detectable metastases, chronic bronchitis, viral encephalitis, iron-deficiency anaemia, or bronchiectasis. One patient was a 75 year old man admitted for social reasons. No control had any clinical evidence of liver disease, and all had normal values for the liver function tests described below. None had a previous history of liver disease or jaundice, and none admitted to a daily alcohol intake greater than $50 \mathrm{~g}$ in the previous 10 years. All subjects had normal concentrations of cholesterol and triglyceride in fasting plasma.

\section{HY PER LIPIDAEMIC SUBJECTS}

Ten consecutive hyperlipidaemia subjects (five male, five female) were studied. Four had ischaemic heart disease without cardiac failure, and one each had idiopathic headaches, Meckel's diverticulum, unilateral gynaecomastia, bronchiectasis, or irritable bowel syndrome. One was an 82 year old woman admitted for social reasons. None had clinical or biochemical evidence of liver disease at the time of the study or a previous history of liver disease. The 
diagnosis of hyperlipidaemia was established on the basis of fasting plasma cholesterol and triglyceride concentrations and also by lipoprotein electrophoresis on agarose gel. None of the hyperlipidaemic subjects was being treated for hyperlipidaemia; three of them had undergone cholecystectomy. Details of the subjects are shown in the Table.

\section{PROCEDURES}

1. Subjects were fasted for 16 hours before the test and $30 \mathrm{ml}$ blood was taken from an antecubital vein for measurement of fasting bile salt concentration, alanine aminotransferase (ALT), aspartate aminotransferase (AST), alkaline phosphatase (AP) and gamma glutamyl transferase (GGT) activities, bilirubin, albumin, total protein, cholesterol and triglyceride concentrations, prothrombin time, and performance of lipoprotein electrophoresis.

2. An intravenous sodium glycocholate tolerance test was performed as previously described. ${ }^{6}$ In brief, a portion of sodium glycocholate solution (Weddel Pharmaceuticals, Wrexham, Clywd, UK), 145 $\mathrm{mmol} / \mathrm{l}$, equivalent to a dose of $5 \mu \mathrm{mol} / \mathrm{kg}$ body weight was taken into a $10 \mathrm{ml}$ syringe together with $1 \mathrm{~g}(5 \mathrm{ml})$ of salt-poor human albumin solution (The Protein Fractionation Centre, Ellen's Glen, Edinburgh, UK). The needle was inserted into an antecubital vein and blood was withdrawn to fill the syringe, allowed to mix for a few seconds and the contents of the syringe were injected. Blood $(2 \mathrm{ml})$ was taken for bile salt analysis from the opposite arm 10 minutes later.

3. Ninety minutes after the injection another blood sample was taken and a standard fatty meal comprising $120 \mathrm{ml}$ fruit yoghurt mixed with an equal volume of fresh cream was given. A sample of blood

Table Fasting cholesterol, triglyceride, and lipoprotein electrophoresis analysis from group of 10 subjects with untreated hyperlipidaemia

\begin{tabular}{|c|c|c|c|c|}
\hline $\begin{array}{l}\text { Age } \\
(y r)\end{array}$ & $\operatorname{Sex}$ & $\begin{array}{l}\text { Cholesterol } \\
(\mathrm{mmol} / \mathrm{l})\end{array}$ & $\begin{array}{l}\text { Triglyceride } \\
(\mathrm{mmol} / \mathrm{l})\end{array}$ & $\begin{array}{l}\text { Lipoprotein } \\
\text { electrophoresis }\end{array}$ \\
\hline 70 & $\mathbf{F}$ & $7 \cdot 7$ & $0 \cdot 8$ & Type IIa \\
\hline 47 & $\mathbf{M}$ & $8 \cdot 3$ & $1 \cdot 2$ & Type IIa \\
\hline 58 & F & $8 \cdot 4$ & $1 \cdot 4$ & Type IIa \\
\hline 46 & $\mathbf{M}$ & $11 \cdot 0$ & $1 \cdot 7$ & Type IIa \\
\hline 53 & $\mathbf{F}$ & $7 \cdot 6$ & $4 \cdot 2$ & Type IIb \\
\hline$* 73$ & $\mathbf{F}$ & $7 \cdot 7$ & $5 \cdot 2$ & Type IV \\
\hline *82 & $\mathbf{F}$ & $5 \cdot 2$ & $1 \cdot 8$ & $\begin{array}{l}\text { Increased Pre- } \beta \\
\text { lipoprotein }\end{array}$ \\
\hline 60 & $\mathbf{M}$ & $4 \cdot 8$ & $1 \cdot 9$ & $\begin{array}{l}\text { Increased Pre- } \beta \\
\text { lipoprotein }\end{array}$ \\
\hline *72 & $\mathbf{M}$ & $4 \cdot 7$ & $2 \cdot 0$ & $\begin{array}{l}\text { Increased Pre- } \beta \\
\text { lipoprotein }\end{array}$ \\
\hline 75 & $\mathbf{M}$ & $5 \cdot 6$ & $2 \cdot 2$ & $\begin{array}{l}\text { Increased Pre- } \beta \\
\text { lipoprotein }\end{array}$ \\
\hline
\end{tabular}

* Patients who had undergone cholecystectomy.

Reference ranges for cholesterol, 3·6-6.7 mmol/1 and for triglycerides, 0.6-1.7 $\mathrm{mmol} / 1$.
( $2 \mathrm{ml}$ ) was taken $1 \frac{1}{2}$ hours after the meal for serum bile salt analysis. In each case the serum bile salt concentration at 90 minutes had returned to the fasting value. This test was not carried out on the subjects who had undergone cholecystectomy.

\section{ASSAY OF LIVER FUNCTION TESTS AND FASTING} LIPID CONCENTRATIONS

Analysis of plasma for ALT, AST, AP activities and bilirubin, albumin, cholesterol, and triglyceride concentrations was carried out on a sequential multiple analysis with computer system (Technicon Instruments Corporation, Basingstoke, UK). Plasma GGT activity was measured on an LKB 8600 reaction rate analyser (LKB Instruments Ltd., Croydon, Surrey, UK) using gamma glutamyl-p-nitroanilide as substrate. Lipoprotein electrophoresis was carried out on $1 \frac{1}{2} \%$ agarose gel and stained with Fat Red 7B (Corning-EEL, Halstead, UK).

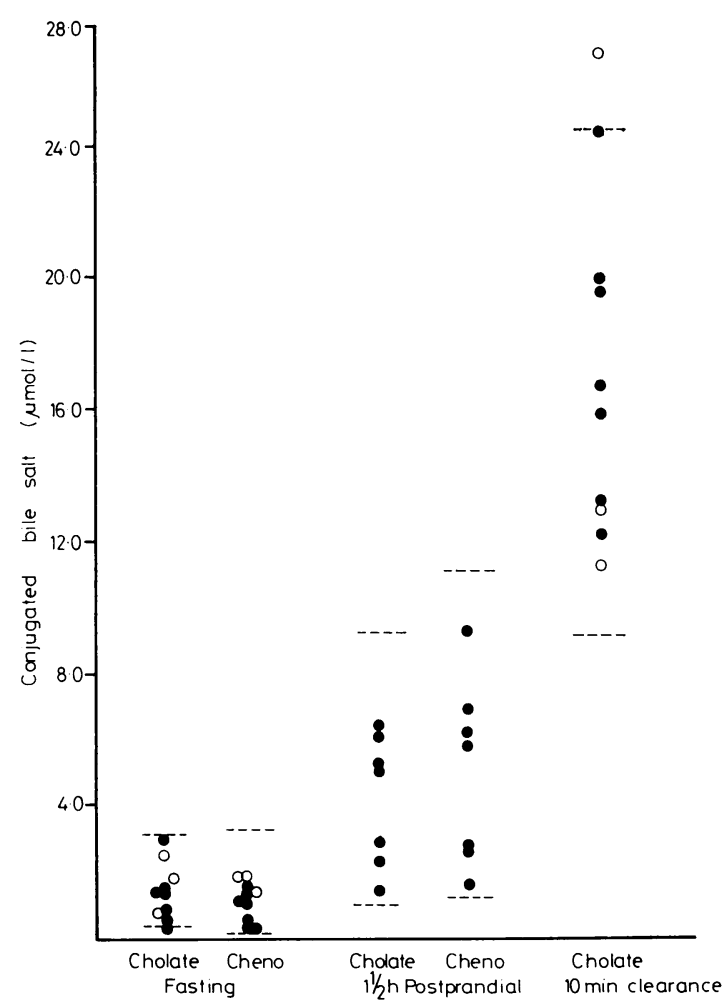

Figure Fasting and $1 \frac{1}{2}$ hour postprandial conjugated cholate and chenodeoxycholate concentrations in the serum of the 10 subjects with hyperlipidaemia. The concentrations of glycocholate in the serum of the same subjects 10 minutes after injection of a dose ( $5 \mu \mathrm{mol} / \mathrm{kg}$ body weight) of glycocholate is also shown. 0: subjects with a cholecystectomy. . . . . : upper and lower limits of the reference range derived from the 13 control subjects. 
ASSAY OF BILE SALTS

Conjugated cholate and conjugated chenodeoxycholate in serum were assayed by a radioimmunoassay using ${ }^{125}$ I-labelled histamine-bile salt as ligand. ${ }^{7,8}$

\section{Results}

The fasting and postprandial concentrations of conjugated cholate and chenodeoxycholate in the serum of hyperlipidaemic subjects are shown in the Figure. The concentration of glycocholate in the same subjects 10 minutes after injection of glycocholate is also shown.

In every hyperlipidaemic subject both the fasting and postprandial bile salt concentrations were within the reference range. The clearance of the injected dose of glycocholate was normal in all but one subject in whom the value was $12 \%$ above the upper limit of the reference range.

\section{Discussion}

We have been unable to confirm the findings reported by Pennington et al., ${ }^{5}$ that the concentrations of conjugated cholate or chenodeoxycholate are raised in the serum of fasting subjects with hyperlipidaemia. Furthermore, we have extended the studies of Pennington et al. ${ }^{5}$ to show that the bile salt concentrations were normal $1 \frac{1}{2}$ hours after a fat-containing meal and that in all but one subject, aged 82 years, the clearance of intravenously administered glycocholate was also normal. Bromsulphthalein clearance is known to be negatively correlated with age $^{9}$ and, as we have shown that glycocholate clearance diminishes with age, ${ }^{6}$ it seems likely that the single minor abnormality in glycocholate clearance was due to the age of this subject.

Pennington et al. ${ }^{5}$ reported that all of their hypolipidaemic subjects had ursodeoxycholate present in the plasma in proportions as great as $33 \%$ of the total bile salts. Nonetheless, cholate and chenodeoxycholate remained the predominant bile salts. Our radioimmunoassays are specific for conjugates of cholate and chenodeoxycholate and therefore the measurements which we have reported should be comparable with the total bile salt concentrations reported by Pennington and his colleagues. Other possible explanations of the discrepancies between the results of the two studies are that the raised total bile salt concentrations found by Pennington et al. were all due to unconjugated bile salts or to secondary bile salts, neither of which would be detected in our radioimmunoassays. Both of these possibilities seem highly unlikely, as neither group of subjects had symptoms of the stagnant loop syn- drome, which may lead to increased plasma unconjugated bile salt concentrations, ${ }^{10}$ and the proportion of deoxycholate in the plasma of the hyperlipidaemic subjects reported by Pennington et al. was actually reduced.

Both our patients and those reported by Pennington and his colleagues had normal liver function tests, and it therefore seems unlikely that unrecognised liver disease could explain the discrepancies. There is, however, known to be a rise in serum bile salt concentration in normal subjects about $1 \frac{1}{2}$ hours after a meal ${ }^{1}$ and a failure to collect samples from adequately fasted patients could lead to apparently abnormal concentrations. This may be of particular importance in the study carried out by Pennington and his colleagues, as all their hyperlipidaemic subjects were outpatients. However, this seems an unlikely explanation, as raised bile salt concentrations were found in nine out of 12 of their patients; this would be a very high false positive rate. The degree of hyperlipidaemia may be another possible reason for the discrepancy between the studies. However, this, too, seems unlikely, as five of our patients had either cholesterol or triglyceride concentrations above the values used by Pennington and his colleagues in selecting patients for study. It seems more likely that differences in the methods used for bile salt assays may explain the discrepancies. While our method is based on specific radioimmunoassays, which require no extraction procedures, Pennington et al. extracted serum and then used gas-liquid chromatography which was not linked to a specific identification procedure such as mass spectrometry. It is possible that subjects with hyperlipidaemia have in their serum substances which run together with the bile salts on the gas liquid chromatography system.

We have found that, when measured by radioimmunoassay, fasting and postprandial serum concentrations of the primary bile salts, and the clearance of injected glycocholate, are not abnormal in hyperlipidaemia. Hyperlipidaemia does not therefore appear to interfere with the apparent liver specificity of the bile salt tests when performed as described here.

\section{References}

${ }^{1}$ Kaplowitz N, Kok E, Javitt NB. Postprandial serum bile acid for the detection of hepatobiliary disease. JAMA 1973; 225: 292-3.

${ }^{2}$ LaRusso NF, Hoffman NE, Hofmann AF, Korman MG. Validity and sensitivity of an intravenous bile acid tolerance test in patients with liver disease. $N$ Engl J Med 1975; 292: 1209-14.

${ }^{3}$ Fausa O, Gjone E. Serum bile acid concentrations in 
patients with liver disease Scand J Gastroenterol, 1976; 11 : 437-43.

${ }^{4}$ Pennington CR, Ross PE, Bouchier IAD. Serum bile acids in the diagnosis of hepatobiliary disease. Gut 1977; 18: 903-8.

${ }^{5}$ Pennington CR, Ross PE, Bateson MC, Bouchier IAD. Serum bile acids in patients with hyperlipidaemia. J Clin Pathol 1978; 31 : 58-62.

${ }^{6}$ Beckett GJ, Douglas JG, Finlayson NDC, Percy-Robb IW. The intravenous sodium glycocholate test, effect of age. Clin Chim Acta 1980; 100: 193-200.

${ }^{7}$ Beckett GJ, Hunter WM, Percy-Robb IW. Investigations into the choice of immunogen, ligand, antiserum and assay conditions for the radioimmunoassay of conjugated cholic acid. Clin Chim Acta, 1978; 88: 257-66.

${ }^{8}$ Beckett GJ, Corrie JET, Percy-Robb IW. The preparation of ${ }^{125}$ I-labelled bile acid ligands for use in the radioimmunoassay of bile acids. Clin Chim Acta 1979; 93: $145-50$.

${ }^{9}$ Thompson EN, Williams R. Effect of age on liver function with particular reference to bromsulphalein excretion. Gut 1965; 6: 266-9.

${ }^{10}$ Lewis B, Panveliwalla D, Tabaqchali S, Wootton IDP. Serum-bile-acids in the stagnant-loop syndrome. Lancet 1969; 1: 219-20. 